TITLE:

\title{
Through-space conjugated polymer containing [2.2] paracyclophane and dithiafulvene units in the main chain
}

\author{
$\operatorname{AUTHOR(S):~}$
}

Morisaki, Yasuhiro; Lin, Lin; Chujo, Yoshiki

\section{CITATION:}

Morisaki, Yasuhiro ...[et al]. Through-space conjugated polymer containing

[2.2] paracyclophane and dithiafulvene units in the main chain. Polymer Bulletin 2009,

62(6): 737-747

\section{ISSUE DATE:}

2009-06

URL:

http://hdl.handle.net/2433/123388

\section{RIGHT:}

Copyright (C) 2009 Springer; This is not the published version. Please cite only the published version.; この論文は出版社版でありません。引用の 際には出版社版をご確認ご利用ください。 


\title{
Through-space Conjugated Polymer Containing [2.2]Paracyclophane and Dithiafulvene Units in the Main Chain
}

\author{
Yasuhiro Morisaki (凶), Lin Lin, Yoshiki Chujo (凶) \\ Department of Polymer Chemistry, Graduate School of Engineering, Kyoto University, Katsura, \\ Nishikyo-ku, Kyoto 615-8510, Japan \\ E-mail: ymo@chujo.synchem.kyoto-u.ac.jp or chujo@chujo.synchem.kyoto-u.ac.jp; Fax: +81 \\ 753832605
}

Received: /Revised version: / Accepted:

\begin{abstract}
Summary
A new through-space conjugated polymer containing alternate [2.2]paracyclophane and dithiafulvene units was synthesized by cycloaddition polymerization of aldothioketene derived from 4,16-diethynyl[2.2]paracyclophane. The obtained polymer was soluble in common organic solvents and could form thin films. UV-vis absorption spectrum of the polymer revealed that its conjugation length increased due to the through-space interaction of the [2.2]paracyclophane units. The polymer formed a charge transfer (CT) complex with 7,7,8,8-tetracyanoquinodimethane (TCNQ) in DMSO.
\end{abstract}

\section{Introduction}

Conjugated polymers are one of the most promising functional materials, because they can be used in the fabrication of conducting devices [1,2], light-emitting diodes [3], field effect transistors [2], etc. Their optical and electronic properties can be easily tuned by changing the components of their backbones and modifying their structures. A number of aromatic compounds have been incorporated into conjugated polymers, and their physical properties have been studied.

[2.2]Paracyclophane is a fascinating molecule comprising two benzene rings closely linked (a distance of approximately $2.8-3.1 \AA$ ) by two ethylene bridges. Since the first preparation of [2.2]paracyclophane in 1949 [4], cyclophane chemistry has attracted significant attention. As the two benzene rings are very close to each other, [2.2]paracyclophane and its derivatives exhibit a transannular $\pi-\pi$ interaction, which leads to a unique extended through-space $\pi$-conjugation $[5,6]$. A variety of [2.2]paracyclophane derivatives have been prepared so far, and their structural features and physical properties have been investigated in detail [5]. There are several reports on the synthesis of polymers containing [m.n]paracyclophane $(\mathrm{m} \leq 3, \mathrm{n}$ $\leq 3)$ by chain polymerization [7-9] and polycondensation techniques [10,11]. However, despite the fact that conjugated polymers have an impressive conjugation system, a few studies have been conducted on the synthesis of conjugated polymers with [2.2]paracyclophane in the polymer main chain $[12,13]$. Recently, we focused on the synthesis of through-space conjugated polymers with [2.2]paracyclophane as 
the repeating unit in the polymer main chain [14-16]. We found that their conjugation length increased via the through-space interaction of the benzene rings. In addition, they exhibited intense blue-orange fluorescence emissions, irrespective of their $\pi$-stacked structures in the polymer main chain.

Cycloaddition of aldothioketene proceeds smoothly under a mild reaction condition, producing a dithiafulvene skeleton [17]. In our previous studies, we prepared a series of conjugated polymers containing a dithiafulvene unit by cycloaddition polymerization [18]. This method enables the incorporation of a variety of aromatic compounds in the conjugated polymer backbone containing dithiafulvene. In this study, we demonstrated the cycloaddition polymerization of a 4,16-diethynyl[2.2]paracyclophane monomer in order to expand the substrate scope of the cycloaddition polymerization of cyclophane compounds as well as to elucidate the electrochemical behaviors of the [2.2]paracyclophane-containing conjugated polymer by exploiting the through-space interaction.

\section{Experimental}

\section{General}

${ }^{1} \mathrm{H}$ and ${ }^{13} \mathrm{C}$ NMR were recorded on a JEOL 400 instrument at $400 \mathrm{MHz}$ and $100 \mathrm{MHz}$, respectively. All samples were analyzed in $\mathrm{CDCl}_{3}$ or DMSO- $d_{6}$, and chemical shift values were expressed relative to $\mathrm{Me}_{4} \mathrm{Si}$ as an internal standard. IR spectra were obtained on a Perkin-Elmer 1600 spectrometer. UV-vis measurements were carried out on a JASCO V-530 spectrophotometer at room temperature. Photoluminescence spectra were recorded on a Perkin-Elmer LS50B luminescence spectrometer at room temperature. Gel permeation chromatography (GPC) was carried out on a UV-8020 and RI-8020 (TSK-GEL a-3000) using DMF containing $10 \mathrm{mM} \mathrm{LiBr}$ as an eluent after calibration with standard polystyrene. For cyclic voltammetry, a polymer thin film was obtained from a DMSO solution on an indium-tin-oxide (ITO) coated glass electrode. Cyclic voltammetry was carried out on a BAS CV-50W electrochemical analyzer in $\mathrm{CH}_{3} \mathrm{CN}$ containing $0.1 \mathrm{M} \mathrm{Et}_{4} \mathrm{NBF}_{4}$ with a $\mathrm{Pt}$ counter electrode and an $\mathrm{Ag} / \mathrm{Ag}^{+}$pseudo-reference electrode at a scan rate of $100 \mathrm{mV} \mathrm{s}{ }^{-1}$. Electrical conductivity of a thin film was measured at room temperature with a four-probe technique using a Loresta-EP MCP-T360 (Mitsubishi Chemical Corp.). High-resolution mass spectra (HRMS) were obtained on a JEOL JMS-SX102A spectrometer. Elemental analysis was carried out on a vario MICRO elemental analyzer (Elementar Analysensysteme GmbH).

\section{Materials}

THF was purified by passage through solvent purification columns under Ar pressure [19]. Dehydrated DMSO and DMF were purchased from Wako Pure Chemicals Industries and used without further purification. $n$-BuLi (1.6 $\mathrm{M}$ in hexane) was purchased from Kanto Chemical Co., Inc. Dioctylamine and $\mathrm{S}_{8}$ were purchased from Wako Pure Chemicals Industries, Ltd. 7,7,8,8-Tetracyanoquinodimethane (TCNQ) was purchased from Tokyo Chemical Industry Co., Ltd. 4,16-Diethynyl[2.2]paracyclophane 1 was synthesized according to the literature [15f]. 


\section{Polymerization}

To a solution of 4,16-diethynyl[2.2]paracyclophane 1 (120 mg, $0.47 \mathrm{mmol})$ in THF $(5.0 \mathrm{~mL}), n$-BuLi in hexane $(1.6 \mathrm{M}, 0.75 \mathrm{~mL}, 1.2 \mathrm{mmol})$ was added dropwise at $0^{\circ} \mathrm{C}$. After stirring for $1 \mathrm{~h}$, the powder of $\mathrm{S}_{8}(34 \mathrm{mg}, 1.1 \mathrm{mmol})$ was added to the solution. The reaction mixture was stirred for $2 \mathrm{~h}$. The reaction mixture was cooled to $-78^{\circ} \mathrm{C}$, and water $(17 \mu \mathrm{L})$ was carefully added. Then the mixture was allowed to warm to room temperature and the reaction mixture was stirred for $2 \mathrm{~h}$. Finally, to the mixture was added dioctylamine $(0.15 \mathrm{~mL})$ and stirred for $13 \mathrm{~h}$. The mixture was then poured into a large amount of $\mathrm{Et}_{2} \mathrm{O}$. The obtained precipitate was washed with $\mathrm{Et}_{2} \mathrm{O}$ and $\mathrm{THF}$ for several times to remove the unreacted dioctylamine, followed by washing with water to remove inorganic salts. After drying the polymer under reduced pressure, an orange powder was obtained.

Yield: $57 \%$. ${ }^{1} \mathrm{H}$ NMR (400 MHz, DMSO- $d_{6}$ ): $\delta 0.8$ (br s, $-\mathrm{Me}$ ), 1.0-2.0 (br m, $\left.-\left(\mathrm{CH}_{2}\right)_{2}-\right), 2.7-3.8$ (br m, bridged $-\left(\mathrm{CH}_{2}\right)_{2}-$ of [2.2] paracyclophane and $\left.\mathrm{N}-\mathrm{CH}_{2}-\right), 5.9$ $(\mathrm{m}, \mathrm{C}=\mathrm{C}-\mathrm{H}), 6.2-7.0$ (br, Ar-H of [2.2]cyclophane and dibenzofulvene ring). IR (KBr): 1610, 1505, 1495, 1195.

\section{2-Ethynyl-p-xylene 3}

2-Ethynyl- $p$-xylene 3 was synthesized by the standard Sonogashira coupling reaction and deprotection. 2-Bromo- $p$-xylene $(2.6 \mathrm{~g}, 14.3 \mathrm{mmol})$, trimethylsilylacetylene (14.3 mL), $\mathrm{PdCl}_{2}\left(\mathrm{PPh}_{3}\right)_{2}(0.67 \mathrm{~g}, 0.96 \mathrm{mmol}), \mathrm{PPh}_{3}$ (0.74 g $\left.2.86 \mathrm{mmol}\right), \mathrm{CuI}$ (0.29 g, $1.43 \mathrm{mmol})$ were dissolved in THF $(27 \mathrm{~mL})$ and $\mathrm{NEt}_{3}(18 \mathrm{~mL})$. The reaction mixture was stirred at $75^{\circ} \mathrm{C}$ for $19 \mathrm{~h}$ under Ar. Precipitated ammonium salts were filtered, and the filtrate was evaporated under reduced pressure. The residue was subjected to column chromatography on $\mathrm{SiO}_{2}$ with hexane to obtain 2-trimethylsilylethynyl- $p$-xylene as a white solid $(1.9 \mathrm{~g}, 9.6 \mathrm{mmol}, 67 \%)$. To a solution of 2-trimethylsilylethynyl- $p$-xylene $(1.9 \mathrm{~g}, 9.6 \mathrm{mmol})$ in THF $(35 \mathrm{~mL})$ was added $\mathrm{Bu}_{4} \mathrm{NF}(10 \mathrm{ml}, 1.0 \mathrm{M}$ in THF). The reaction mixture was stirred at room temperature overnight under Ar. The solution was evaporated under reduced pressure, and the residue was purified by HPLC to afford 3 as a white solid $(0.82 \mathrm{~g}$, $6.3 \mathrm{mmol}, 66 \%$ ). The analysis data agree with the literature's values [20].

\section{Model compound 4}

To a solution of 2-ethynyl- $p$-xylene $3(0.13 \mathrm{~g}, 1.0 \mathrm{mmol})$ in $\mathrm{Et}_{2} \mathrm{O}(2.0 \mathrm{~mL}), n$-BuLi in hexane $(1.6 \mathrm{M}, 1.0 \mathrm{~mL}, 1.6 \mathrm{mmol})$ was added at $0^{\circ} \mathrm{C}$. After stirring for $1.5 \mathrm{~h}$, the powder of $\mathrm{S}_{8}(50 \mathrm{mg}, 1.1 \mathrm{mmol})$ was added to the solution. The reaction mixture was stirred for $2 \mathrm{~h}$, and cooled to $-78^{\circ} \mathrm{C}$. Water $(30 \mu \mathrm{L})$ was carefully added. The mixture was allowed to warm to room temperature and stirred for $12 \mathrm{~h}$. The mixture was extracted with $\mathrm{Et}_{2} \mathrm{O}$, followed by washing with saturated $\mathrm{NaCl}$ aq. The organic layer was dried over $\mathrm{Na}_{2} \mathrm{SO}_{4}$, and then, the solvent was dried in vacuo. The residue was subjected to column chromatography on $\mathrm{SiO}_{2}$ with hexane to afford $\mathbf{4}$ as a yellow solid.

Yield 29\%. $\quad R_{f}=0.68\left(\mathrm{SiO}_{2}\right.$, hexane $\left./ \mathrm{CH}_{2} \mathrm{Cl}_{2}, \mathrm{v} / \mathrm{v}=2: 1\right) .{ }^{1} \mathrm{H}$ NMR $(400 \mathrm{MHz}$, $\left.\mathrm{CDCl}_{3}\right): \delta 2.29\left(\mathrm{~m}, 12 \mathrm{H},-\mathrm{CH}_{3}\right), 5.91(\mathrm{~s}, 0.45 \mathrm{H},(E)-\mathrm{C}=\mathrm{C}-\mathrm{H}), 6.02(\mathrm{~s}, 0.55 \mathrm{H}$, $(Z)-\mathrm{C}=\mathrm{C}-\mathrm{H}), 6.51(\mathrm{~s}, 0.55 \mathrm{H},(Z)$-dithiafulvene ring proton), $6.54 \quad(\mathrm{~s}, 0.45 \mathrm{H}$, (E)-dibenzofulvene ring proton), 6.86-7.24 (m, 6H, aromatic protons). ${ }^{13} \mathrm{C} \mathrm{NMR}$ 
$\left(100 \mathrm{MHz}, \mathrm{CDCl}_{3}\right): \delta 19.51,19.54,19.83,19.89,20.69,20.71,21.10,21.12,110.58$, $110.05,113.61,113.63,125.98,126.06,126.72,126.79,129.45,129.48,129.98$, $130.03,130.29,130.39,130.56,130.61,131.70,131.75,131.87,132.13,132.66$, $132.99,133.46,133.61,135.17,135.20,135.45,135.48,135.71,135.76,136.75$, 137.09. HRMS (EI): $\mathrm{m} / \mathrm{z}$ calcd for $\mathrm{C}_{20} \mathrm{H}_{20} \mathrm{~S}_{2}\left(\mathrm{M}^{+}\right): 324.1006$. Found: 324.1002 . Anal. calcd for $\mathrm{C}_{20} \mathrm{H}_{20} \mathrm{~S}_{2}$ : C, 74.03; H, 6.21; S, 19.76. Found: C, 73.67; H, 6.18; S, 19.78 .

\section{Results and Discussion}

4,16-Diethynyl[2.2]paracyclophane 1 can be easily prepared from commercially available [2.2]paracyclophane [15f]. Scheme 1 outlines the synthetic procedure of the target polymer 2. Treatment of 1 with $n$-BuLi and sulfur $\mathrm{S}_{8}$ at $0^{\circ} \mathrm{C}$ in succession afforded diethynethiolate, which was reacted with a small amount of $\mathrm{H}_{2} \mathrm{O}$ at $-78^{\circ} \mathrm{C}$ to produce diethynethiol. Thioketene was formed by tautomerization in situ and reacted with ethynethiol to obtain the polymer containing dithiafulvene units. Finally, octylamine was added to quench the polymerization and to improve the solubility of the polymer. After purification of the crude polymer by washing with $\mathrm{Et}_{2} \mathrm{O}$, THF, and $\mathrm{H}_{2} \mathrm{O}$, polymer 2 was obtained in $57 \%$ isolated yield. The molecular weights of the polymers were measured by GPC (eluent: DMF) and calculated by using polystyrene standards. The number-average molecular weight $\left(M_{\mathrm{n}}\right)$ and the weight-average molecular weight $\left(M_{\mathrm{w}}\right)$ were $M_{\mathrm{n}}=7200$ and $M_{\mathrm{w}}=9300$, respectively. Polymer 2 could be dissolved in aprotic solvents such as DMSO and DMF. A thin film of 2 could be readily obtained by a casting or spin-coating method.
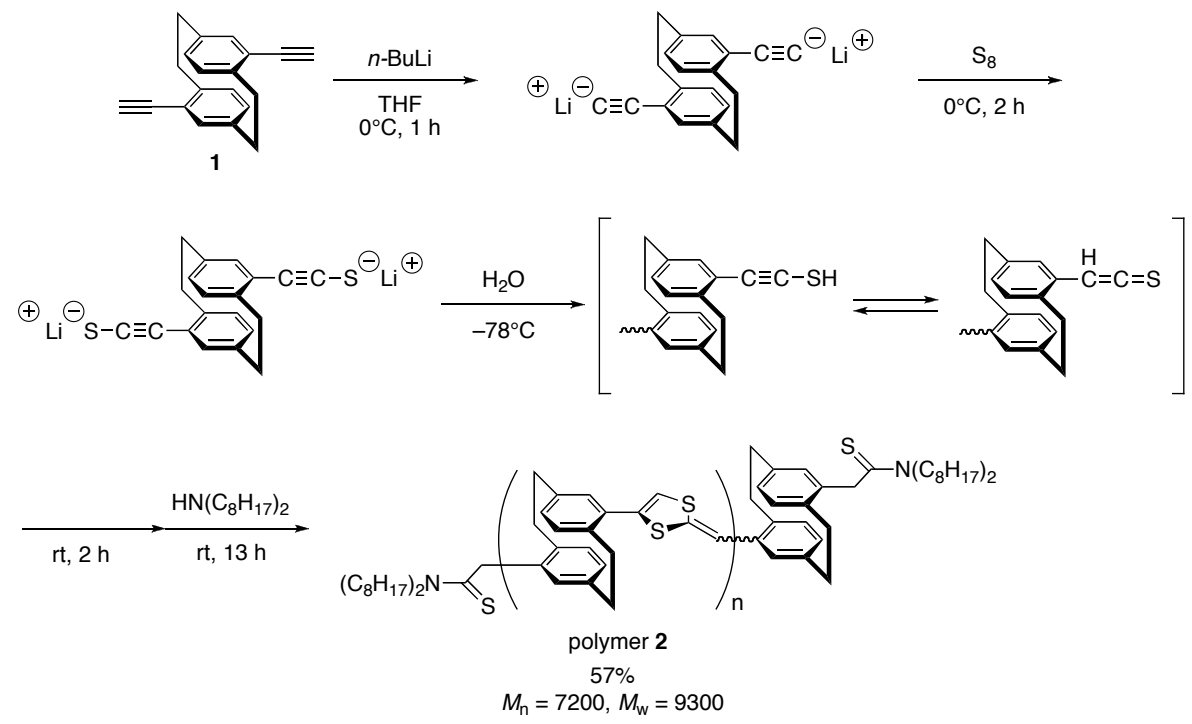

Scheme 1. Synthesis of polymer 2

The structure of polymer 2 was confirmed by ${ }^{1} \mathrm{H}$ NMR and IR spectra. The ${ }^{1} \mathrm{H}$ NMR spectrum of 2 in DMSO- $d_{6}(400 \mathrm{MHz})$ is shown in Figure 1 . Signals at $0.8 \mathrm{ppm}$ and 1.0-2.0 ppm were assigned to $-\mathrm{Me}$ and $-\left(\mathrm{CH}_{2}\right)_{6}-$ in the alkyl chains of the end-capped 
dioctylamine moieties, respectively. The signals of $-\mathrm{NCH}_{2}-$ groups overlapped with those of DMSO and bridged methylenes of [2.2]paracyclophane. Peaks of the bridged methylene protons of the [2.2]paracyclophane units were observed at around 2.7-3.8 ppm as broad signals, which overlapped with those of $\mathrm{H}_{2} \mathrm{O}$ and DMSO. The benzylidene protons were observed at around $5.9 \mathrm{ppm}$, which are considered to be a mixture of $(E)$ - and (Z)-isomers. Signals of the aromatic protons in the [2.2]paracyclophane moieties appeared at $6.2-7.0 \mathrm{ppm}$ due to the ring current effect, which overlapped with the signals of ring protons in the dithiafulvene moieties.

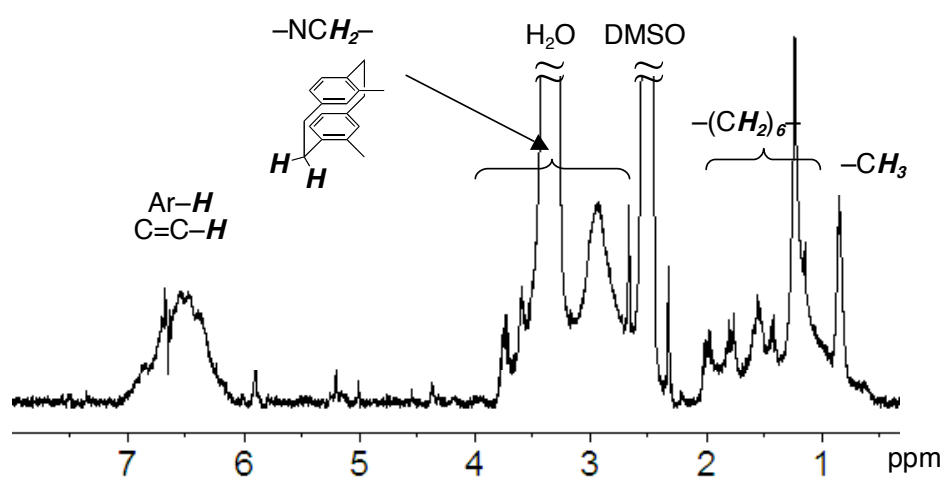

Figure 1. ${ }^{1} \mathrm{H}$ NMR spectrum of polymer $\mathbf{2}$ in DMSO- $d_{6}$.

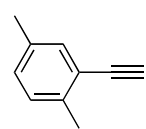

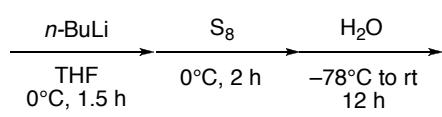

$0^{\circ} \mathrm{C}, 1.5 \mathrm{~h}$

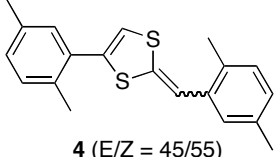

$13 \%$

Figure 2 shows a comparison between the UV-vis absorption spectra of polymer 2 and model compound $4(E / Z=45 / 55)$, which was prepared by dimerization of aldothioketene derived from 2-ethynyl- $p$-xylene 3 (Scheme 2). The absorption maximum of polymer $\mathbf{2}$ in DMSO was observed at $378 \mathrm{~nm}$. This maximum was attributed to the $\pi-\pi^{*}$ transition of the conjugated polymer backbone. The absorption maximum of model compound 4 was observed at 352 $\mathrm{nm}$. The through-space interaction of co-facial benzene rings in the [2.2]paracyclophane moiety resulted in the extension of the $\pi$-conjugation length throughout the polymer chain. On the other hand, the absorption maximum of

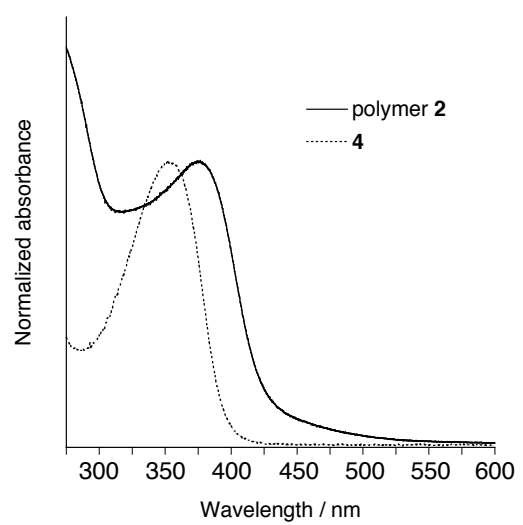

Figure 2. UV-vis absorption spectra of polymer 2 and compound $\mathbf{4}$ in DMSO (1.0 $\left.\times 10^{-5} \mathrm{M}\right)$. 
the through-bond conjugated polymer 5 in $\mathrm{CH}_{3} \mathrm{CN}$ appears at $398 \mathrm{~nm}$ [18a,b]. The through-bond conjugation is more effective for the extension of $\pi$-conjugation than the through-space conjugations [14].

The electrochemical behavior of polymer $\mathbf{2}$ was investigated by cyclic voltammetry $(\mathrm{CV})$. The CV measurement of a cast film of $\mathbf{2}$ was performed in dry $\mathrm{CH}_{3} \mathrm{CN}$ with $0.1 \mathrm{M}$ $\mathrm{NEt}_{4} \mathrm{BF}_{4}$ at room temperature and a scan rate of $100 \mathrm{mV} \mathrm{s}^{-1}$. The cyclic voltammogram is shown in Figure 3. Polymer $\mathbf{2}$ exhibited a single broad irreversible oxidation peak at around $0.63 \mathrm{~V}$ (vs. $\mathrm{Ag} / \mathrm{Ag}^{+}$). In the previous study, it was found that polymer 5 exhibited an irreversible oxidation peak at $0.61 \mathrm{~V}$ (vs. $\mathrm{Ag} / \mathrm{Ag}^{+}$) [18b]. The $\pi$-stacked structure of 2 did not affect the redox behavior of the dithiafulvene unit [15f]; hence, the difference in the peak potential of the dithiafulvene unit between $\mathbf{2}$ and $\mathbf{5}$ was small. This result indicates that extension of $\pi$-conjugation length of $\mathbf{2}$ via the through-space interaction would be similar to that of $\mathbf{5}$ via the through-bond interaction [18b].

A charge-transfer (CT) complex formation of polymer $\mathbf{2}$ with 7,7,8,8-tetracyanoquinodimethane

(TCNQ) was examined. It is known that both the dithiafulvene unit [18c] and the [2.2]paracyclophane unit [21] form the CT complex. Figure 4 shows the dependence of the UV spectrum of $\mathbf{2}$ on the TCNQ feed ratio against the [2.2]paracyclophane unit in DMSO. Absorption peaks observed in the range of 600-1000 $\mathrm{nm}$ were derived from the anion radical of TCNQ by CT complexation. Absorbance due to CT complexation with TCNQ increased with the addition of TCNQ. The absorbance in the range of 600-1000 nm was saturated when the feed ratio, [TCNQ]/[repeating unit], was 2.0. A further increase in the feed ratio of TCNQ did not affect the absorption of the anion radical of TCNQ. The peak intensity ratio of the $400 \mathrm{~nm}$ and $600-1000 \mathrm{~nm}$ band is reported to be approximately 0.50 in the case of simple TCNQ salts [22]. In the present system,

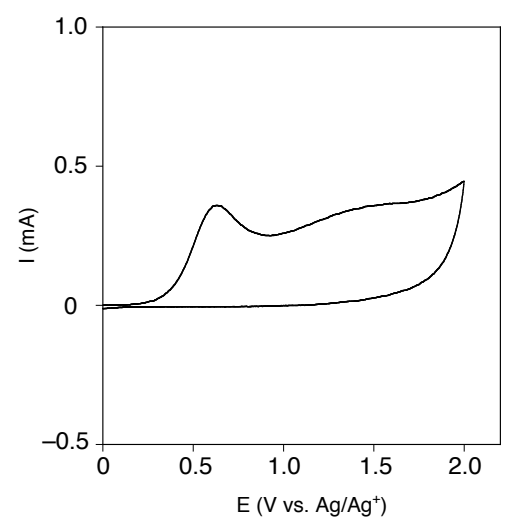

Figure 3. Cyclic votammogram of the cast film of polymer 2 in $\mathrm{CH}_{3} \mathrm{CN}$.
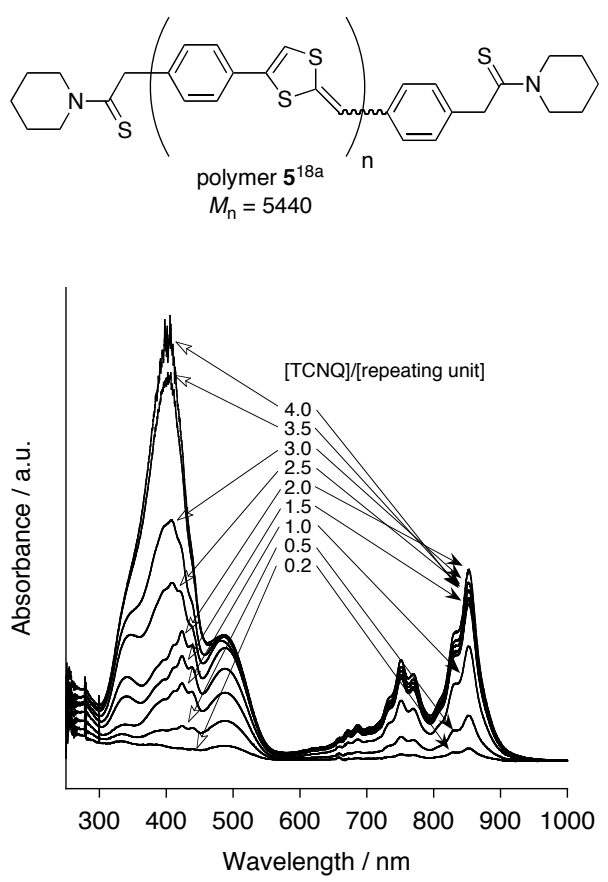

Figure 4. UV-vis absorption spectra of CT complexes of polymer 2 with TCNQ in DMSO (repeating unit $=1.8 \times 10^{-4} \mathrm{M}$ ). 
the intensity ratio was approximately 0.65 at $[\mathrm{TCNQ}] /[$ repeating unit] $=2.0$, which implies a formation of TCNQ complex with dithiafulvene as well as [2.2]paracyclophane units in the repeating unit. The absorption peak at around 400 $\mathrm{nm}$ increased, and it was almost saturated at [TCNQ]/[repeating unit $]=3.5-4.0$. It is considered that excess TCNQ interacts with the conjugated polymer chain.

A thin film of polymer 2 was fabricated by casting from a DMF solution, which had an electrical conductivity of $1 \times 10^{-6} \mathrm{~S} \mathrm{~cm}^{-1}$. Excess TCNQ on the basis of the repeating unit was added to the solution of 2 to form the CT complex, as mentioned above; after filtration of the remaining TCNQ, a dark green solution was dried on ITO to form the thin film of the CT complex. This thin film had an electrical conductivity of $2 \times 10^{-5} \mathrm{~S} \mathrm{~cm}^{-1}$, which was higher than that of the undoped polymer thin film. The polymer was doped with an organic acceptor such as TCNQ by the formation of the CT complex [18c]. On the other hand, the electrical conductivity measurement of polymer 2 by doping with $\mathrm{I}_{2}$ vapor was carried out. The oxidized polymer thin film exhibited a conductivity of $3 \times 10^{-6} \mathrm{~S} \mathrm{~cm}^{-1}$ (exposure time: $2 \mathrm{~h}$ ), $7 \times$ $10^{-4} \mathrm{~S} \mathrm{~cm}^{-1}$ (exposure time: $24 \mathrm{~h}$ ), and $2 \times 10^{-3} \mathrm{~S} \mathrm{~cm}^{-1}$ (exposure time: $30 \mathrm{~h}$ ), which was saturated for an exposure time of $30 \mathrm{~h}\left(2 \times 10^{-3} \mathrm{~S} \mathrm{~cm}^{-1}\right.$, exposure time: $\left.48 \mathrm{~h}\right)$. This value was higher than that obtained by using TCNQ. In addition, the both values of the undoped and doped through-space conjugated polymer $\mathbf{2}$ were slightly higher than those of the through-bond conjugated polymer $\mathbf{5}$ we reported previously [18b]. Further careful investigations about that enhancement of the conductivity arises from the effect of the $\pi$-stacked structure of the through-space conjugated polymer chain are currently in progress.

\section{Conclusion}

The cycloaddition polymerization of aldothioketene could be applied to the cyclophane monomer, 4,16-diethynyl[2.2]paracyclophane, to obtain the corresponding through-space conjugated polymer consisting of alternate dithiafulvene and [2.2]paracyclophane units in the main chain. The polymers exhibited an extension of the conjugation length via the through-space interaction of the [2.2]paracyclophane unit. The polymer formed a CT complex with two equivalents of TCNQ based on the repeating unit. A thin film of the through-space conjugated polymer exhibited electrical conductivities of $2 \times 10^{-5}$ and $2 \times 10^{-3} \mathrm{~S} \mathrm{~cm}^{-1}$ by doping with TCNQ and $\mathrm{I}_{2}$, respectively, which were higher than those of the through-bond conjugated analogue.

Acknowledgements. This work was supported by Grant-in-Aid for Creative Scientific Research of "Invention of Conjugated Electronic Structures and Novel Functions", No. 16GS0209, from the Ministry of Education, Culture, Sports, Science, and Technology, Japan.

\section{References}

1. (a) Skothim TA, Elsenbaumer RL, Reynolds JR (eds) (1998) Handbook of Conducting Polymers, 2nd ed, Marcel Dekker, New York (b) Shirakawa H (2001) Angew Chem Int Ed 40:2574 $\begin{array}{llll}\text { (c) MacDiarmid AG (2001) Angew Chem Int Ed 40:2581 } & \text { (d) Heeger AJ }\end{array}$ (2001) Angew Chem Int Ed 40:2591

2. (a) de Boer B, Facchetti A (2008) 48:423 (b) Pron A, Rannou P (2002) Prog Polym Sci 27:135

3. (a) Shim HK, Jin JI (2002) Adv Polym Sci 158:193 (b) Kraft A, Grimsdale AC, 
Holmes AB (1998) Angew Chem Int Ed 37:402

4. Brown CJ, Farthing, AC (1949) Nature 164:915

5. (a) Vögtle F (1993) Cyclophane Chemistry. Wiley\&Sons, New York (b) Shultz J, Vögtle F (1994) Top Curr Chem 172:42 (c) Cleiter R, Hopf H, Eds. (2004) Modern Cyclophane Chemistry. Wiley-VCH, Weinheim (d) Recent review, see: Hopf H (2008) Angew Chem Int Ed 47:9808

6. (a) Cram DJ, Allinger, NL, Steinberg, H (1954) J Am Chem Soc 76:6132 (b) Heilbronner E, Yang ZZ (1983) Top Curr Chem 115:1 $\quad$ (c) Ganuto S, Zerner MC (1990) J Am Chem Soc 112:2114 (d) Yamakita Y, Yamauchi M, Ohno K (2000) Chem Phys Lett 322:189 (e) Oldham Jr WJ, Miao YJ, Lachicotte RJ, Bazan GC (1998) J Am Chem Soc 120:419 (f) Bazan GC, Oldham Jr WJ, Lachicotte RJ, Tretiak S, Chernyak V, Mukamel S (1998) J Am Chem Soc 120:9188 (g) Wang S, Bazan GC, Tretiak S, Mukamel S (2000) J Am Chem Soc 122:1289

7. (a) Nishimura J, Yamashita S. In: Butler G B, Kresta J E editors. Cyclopolymerization and Polymers with Chain-Ring Structures. Washington, D. C.: American Chemical Society (1982) 177 (b) Furukawa J, Nishimura J (1976) J Polym Sci Polym Lett Ed 14:85 (c) Furukawa J, Nishimura J (1976) J Polym Sci Polym Symp 56:437 (d) Nishimura J, Yamashita S (1979) Polym J 11:619 (e) Nishimura J, Mimura M, Nakazawa N, Yamashita S (1980) J Polym Sci Polym Chem Ed 18:2071 (f) Nishimura J, Furukawa M, Yamashita S, Inazu T, Yoshino T (1981) J Polym Sci Polym Chem Ed 19:3257

8. (a) Glatzhofer DT, Longone DT (1986) J Polym Sci Part A Polym Chem 24:947 (b) Longone DT, Glatzhofer DT (1986) J Polym Sci Part A Polym Chem 24:1725 (c) Ulański J, Kubacki J, Glowacki I, Kryszewski M, Glatzhofer DT (1992) J Appl Polym Sci 44:2103 (d) Ulanski J, Sielski J, Glatzhofer DT, Kryszewski M (1990) J Phys D $23: 75$

9. Iwatsuki S, Itoh T, Kubo M, Okuno H (1994) Polym Bull 32:27

10. Meyers RA, Hamersma JW, Green HA (1972) J Polym Sci B 10

11. (a) Sivaramakrishnan KP, Samyn C, Westerman IJ, Wong DT, Marvel CS (1975) J Polym Sci Polym Chem Ed 13:1083 (b) Chang DM, Marvel CS (1975) J Polym Sci Polym Chem Ed 13:2507 $\quad$ (c) Lin S, Marvel CS (1983) J Polym Sci Polym Chem Ed 21:1151

12. (a) Salhi F, Collard DM (2002) Polym Mater Sci Eng 222 (b) Salhi F, Collard DM (2003) Adv Mater 15:81

13. (a) Guyard L, Audebert P (2001) Elecrochem Commun 3:164 (b) Guyard L, Nguyen Dinh An M, Audebert P (2001) Adv Mater 13:133

14. (a) Morisaki Y, Chujo Y (2006) Angew Chem Int Ed 45:6430 (b) Morisaki Y, Chujo Y (2008) Prog Polym Sci 33:346

15. (a) Morisaki Y, Chujo Y (2002) Macromolecules 35:587 (b) Morisaki Y, Chujo Y (2002) Chem Lett 194 (c) Morisaki Y, Ishida T, Chujo Y (2002) Macromolecules 35:7872 (d) Morisaki Y, Chujo Y (2002) Polym Bull 49:209 (e) Morisaki Y, Fujimura F, Chujo Y (2003) Organometallics 22:3553 (f) Morisaki Y, Chujo Y (2003) Macromolecules 36:9319 (g) Morisaki Y, Chujo Y (2004) Macromolecules 37:4099 (h) Morisaki Y, Ishida T, Tanaka H, Chujo Y (2004) J Polym Sci Part A Polym Chem 42:5891 (i) Morisaki Y, Wada N, Chujo Y (2005) Polym Bull 53:73 (j) Morisaki Y, Wada N, Chujo Y (2005) Polymer 46:5884 $\quad$ (k) Morisaki Y, Chujo Y (2005) Bull Chem Soc Jpn 78:288 (1) Morisaki Y, Wada N, Arita M, Chujo Y (2009) Polym Bull, in press

16. (a) Morisaki Y, Chujo Y (2005) Tetrahedron Lett 46:2533 (b) Morisaki Y, Murakami T, Chujo Y (2008) Macromolecules 41:5960

17. (a) Raap R (1968) Can J Chem 46:2251 (b) Sukhai RS, de Jong R, Verkruijsse HD, Brandsma L (1981) Recl Trav Chim Pays-Bas 100:368 (c) Harris SJ, Walton DRM (1977) J Organomet Chem 127:C1

18. (a) Naka K, Uemura T, Chujo Y (1998) Macromolecules 31:7570 $\quad$ (b) Naka K, Uemura T, Chujo Y (1999) Macromolecules 32:4641 $\quad$ (c) Naka K, Uemura T, Chujo Y (2000) 
Polym J 32:435

19. Pangborn AB, Giardello MA, Grubbs RH, Rosen RK, Timmers FJ (1996) Organometallics 15:1518

20. Negishi E, Kotora M, Xu C (1997) J Org Chem 62:8957

21. Morisaki Y, Shiotani Y, Lin L, Chujo Y (2008) Polym J 40:779

22. (a) Merby LR, Harder RJ, Hertler WR, Mahler W, Benson RE, Mochel WE (1962) 84:3374 (b) Gong JP, Kawakami I, Sergeyev VG, Osada Y (1991) 24:5246 